\title{
Bile Duct Mucinous Cystic Neoplasm with Intermediate Grade Intraepithelial Neoplasia
}

National Cancer Institute

\section{Source}

National Cancer Institute. Bile Duct Mucinous Cystic Neoplasm with Intermediate Grade Intraepithelial Neoplasia. NCI Thesaurus. Code C96837.

A non-invasive mucinous cystic neoplasm that arises from the intrahepatic or extrahepatic bile ducts. It is characterized by the presence of moderate atypia. 